\title{
Effect of Annealing Temperature on Microstructure and Shape Memory Characteristics of Ti-22Nb-6Zr(at\%) Biomedical Alloy
}

\author{
Jae Il Kim ${ }^{1,2}$, Hee Young Kim ${ }^{1}$, Tomonari Inamura ${ }^{3}$, Hideki Hosoda ${ }^{3}$ and Shuichi Miyazaki ${ }^{1, *}$ \\ ${ }^{1}$ Institute of Materials Science, University of Tsukuba, Tsukuba 305-8573, Japan \\ ${ }^{2}$ Materials Science and Engineering, Dong-A University, Busan 604-714, Korea \\ ${ }^{3}$ Precision and Intelligence Laboratory, Tokyo Institute of Technology, Yokohama 226-8503, Japan
}

Effect of annealing temperature on microstructure and shape memory characteristics of Ti-22Nb-6Zr(at\%) biomedical alloys was investigated by using tensile tests, XRD measurement, scanning electron microscopy (SEM) and transmission electron microscopy (TEM). After severe cold-rolling, the plate was annealed at temperatures between 773 and $1173 \mathrm{~K}$. The $\alpha / \beta$ transus temperature in this alloy was determined to be between 823 and $873 \mathrm{~K}$. The specimen annealed at $823 \mathrm{~K}$ for $3.6 \mathrm{ks}$ exhibited a fine subgrain structure. A fully recrystallized structure was observed in the specimens annealed above $873 \mathrm{~K}$. The annealing temperature less affected the transformation temperature and recovery strain. However, the critical stress for slip decreased considerably with increasing annealing temperature, because the grain size increased. All specimens annealed above $823 \mathrm{~K}$ exhibited stable superelastic behavior at room temperature.

(Received November 4, 2005; Accepted December 21, 2005; Published March 15, 2006)

Keywords: shape memory effect, superelasticity, biomaterials, titanium based alloy, titanium-niobium-zirconium, Hall-Petch relationship

\section{Introduction}

Ti-based alloys have been applied as biomedical materials to date due to their high corrosion resistance, high biocompatibility and low Young's modulus. Among biomedical alloys, Ti-Ni alloys have been applied as orthodontic arch wires, bone plates and stents, owing to their unique shape memory effect and superelasticity. However, it has been reported that pure $\mathrm{Ni}$ is a toxic element and causes $\mathrm{Ni}$ hypersensitivity. ${ }^{1)}$ Although clear Ni-hypersensitivity to human body in $\mathrm{Ti}-\mathrm{Ni}$ alloys has not been reported until now, it is preferable to develop absolutely safe Ni-free Tibased shape memory alloys for biomedical applications.

Many $\beta$-type Ti-based alloys have been investigated to date, e.g., Ti-V based alloys, ${ }^{2)} \mathrm{Ti}-\mathrm{Mo}$ based alloys ${ }^{3-8)}$ and $\mathrm{Ti}-\mathrm{Nb}$ based alloys ${ }^{9-15}$ ) since Baker reported the shape memory effect in a Ti-35 mass $\% \mathrm{Nb}$ alloy. ${ }^{9)}$ Considering biomedical applications, the $\mathrm{Ti}-\mathrm{V}$ based alloys are not suitable because of cytotoxicity of $\mathrm{V} .{ }^{16)}$ The shape memory effect in the Ti-based alloys may be affected by the following factors; (1) aging treatment, which may cause precipitation hardening due to $\alpha$ phase and $\omega$ phase and (2) thermomechanical treatment (cold work followed by annealing), which may improve shape memory characteristics by dense dislocations and grain refinement. The fine thermal $\omega$ precipitates formed by aging treatment improve the shape memory properties, because they increase the critical stress for slip. On the other hand, it is known that grain refinement via cold working followed by low temperature annealing may be useful method for improving mechanical properties of alloys. However, no systematic research on the effect of annealing condition on the shape memory characteristics has been carried out in the $\beta$-type Ti-based alloys to date.

Recently, the effect of $\mathrm{Zr}$ addition to the $\mathrm{Ti}-\mathrm{Nb}$ alloy on shape memory characteristics has been reported. ${ }^{15)}$ According to this study, a solution-treated $\mathrm{Ti}-22 \mathrm{Nb}-6 \mathrm{Zr}(\mathrm{at} \%)$ alloy exhibits superior superelastic behavior at room temperature

*Corresponding author, E-mail: miyazaki@ims.tsukuba.ac.jp than $\mathrm{Ti}-\mathrm{Nb}$ binary alloys. In the present study, in order to improve shape memory characteristics of $\mathrm{Ti}-22 \mathrm{Nb}-6 \mathrm{Zr}(\mathrm{at} \%)$ alloy, the effect of annealing temperature on shape memory characteristics were investigated by tensile tests at various temperatures, XRD (X-ray diffraction) measurement, scanning electron microscopy (SEM) and transmission electron microscopy (TEM).

\section{Experimental}

A Ti-22Nb-6Zr(at\%) ingot was fabricated by an Ar arc melting method. The ingot was cold-rolled to a plate of $0.5 \mathrm{~mm}$ in thickness with a final cold working ratio of $95 \%$. Specimens for XRD measurement, tensile tests, SEM observation and TEM observation were cut from the plate by an electro-discharge machine. All the specimens were finally annealed at $773,823,873,973,1073 \mathrm{~K}$ for $3.6 \mathrm{ks}$ and $1173 \mathrm{~K}$ for $1.8 \mathrm{ks}$ in an $\mathrm{Ar}$ atmosphere, followed by quenching into water. After the annealing treatment, the specimens were etched in order to remove oxidized surface. In order to investigate the shape memory characteristics, tensile tests were carried out at a strain rate of $1.67 \times$ $10^{-4} \mathrm{~s}^{-1}$ at various temperatures. The gage length of specimens for tensile tests was $20 \mathrm{~mm}$. XRD measurement was conducted at room temperature with $\mathrm{Cu} \mathrm{K} \alpha$ radiation to determine the constituent phases. Specimen for TEM observation were prepared by a conventional twin-jet polishing technique using an electrolyte solution of $5 \mathrm{vol} \%$ sulfuric acid, 2 vol\% hydrofluoric acid and 93 vol\% methanol at $230 \mathrm{~K}$. The TEM observation was conducted using a JEOL2010F microscope operated at $200 \mathrm{kV}$. Grain size was measured using SEM micrographs.

\section{Results and Discussion}

\subsection{Effect of annealing temperature on microstructure}

In order to identify the constituent phases of each annealed specimens at room temperature, X-ray diffraction measurement was carried out. Figure 1 shows X-ray diffraction 


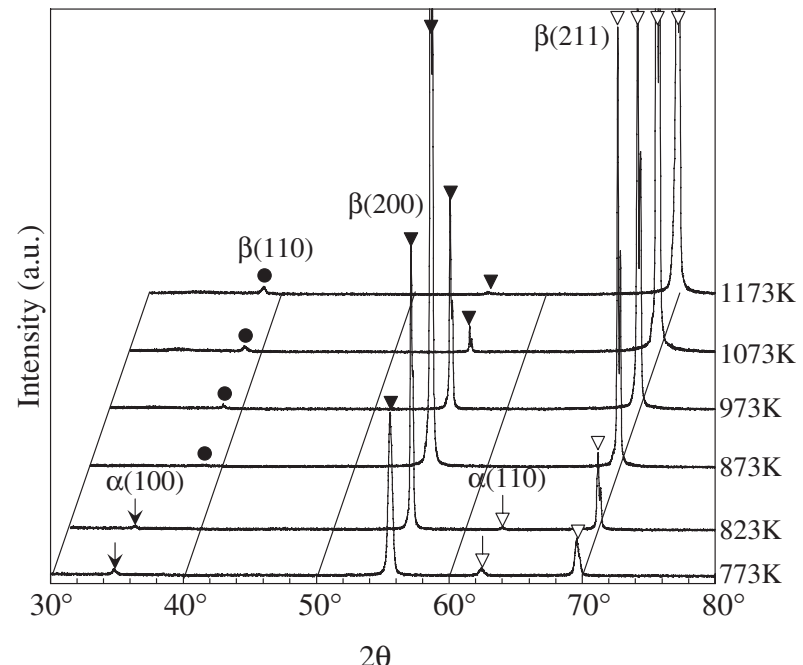

Fig. 1 XRD profiles measured at room temperature in the specimens annealed at temperatures between 773 and $1173 \mathrm{~K}$.

profiles of the specimens annealed at temperatures between 773 and $1173 \mathrm{~K}$. Within the $2 \theta$ range shown in this figure, the $\alpha$ phase is identified by two major reflections from $(100)_{\alpha}$ and $(110)_{\alpha}$, whereas the $\beta$ phase is identified by three major reflections. Comparing with the intensities of $\{211\}_{\beta}$ peak in the specimens annealed at 773 and $823 \mathrm{~K}$, those of $\{200\}_{\beta}$ peak are very strong. It is assumed that this is due to a deformation texture. Kim et $a l{ }^{17)}$ reported that a well developed $\{100\}\langle 110\rangle$ texture was obtained in as-rolled and annealed $\mathrm{Ti}-22 \mathrm{Nb}-6 \mathrm{Ta}$ alloys after severe cold-rolling. On the other hand, the intensities of $\{211\}_{\beta}$ peak are stronger than those of $\{200\}_{\beta}$ peak in the specimens annealed at 1073 and $1173 \mathrm{~K}$. This is due to a recrystallization texture. It has been also reported that a recrystallization texture of $112\langle 110\rangle$ is developed in $\mathrm{Ti}-22 \mathrm{Nb}-6 \mathrm{Ta}^{17)}$ and $\mathrm{Ti}-22 \mathrm{Nb}-3 \mathrm{Al}^{18)}$ alloys heat treated at 1173 and $1273 \mathrm{~K}$, respectively, after severe cold-rolling. Based on previous researches ${ }^{17,18)}$ and present $\mathrm{XRD}$ results, it is expected that the deformation and recrystallization texture of $\mathrm{Ti}-22 \mathrm{Nb}-6 \mathrm{Zr}$ alloy exhibit similar one as those of other $\mathrm{Ti}-\mathrm{Nb}$ based alloys. It is also noted that both of the $\{200\}_{\beta}$ peak and $\{211\}_{\beta}$ peak are strong in the specimen annealed at $873 \mathrm{~K}$ for $3.6 \mathrm{ks}$, indicating that the deformation and recrystallization textures coexist.

While the diffraction peaks corresponding to the $\alpha$ phase are observed in the specimens annealed at 773 and $823 \mathrm{~K}$, there exist only the peaks corresponding to the $\beta$ phase in the specimens annealed above $873 \mathrm{~K}$. This means that the $\alpha / \beta$ transus temperature of this alloy is between 823 and $873 \mathrm{~K}$. According to the $\mathrm{Ti}-\mathrm{Nb}$ binary phase diagram, the $\alpha / \beta$ transus temperature of $\mathrm{Ti}-22 \mathrm{Nb}$ is about $830 \mathrm{~K}$. This indicates that the addition of $\mathrm{Zr}$ does not affect the $\alpha / \beta$ transus temperature significantly. On the other hand, the peaks corresponding to $\alpha^{\prime \prime}$ can not be observed in any specimen. This indicates that the martensitic transformation start temperature $\left(M_{\mathrm{S}}\right)$ of these specimens is below room temperature.

Figure 2 shows the microstructures observed by SEM in the specimens annealed at $873,973,1073$ and $1173 \mathrm{~K}$. It is also clear that no martensite phase $\left(\alpha^{\prime \prime}\right)$ was observed in all annealed specimens. As shown in these figures, any secondary phase can not be observed. The results of these SEM micrographs are well consistent with those of the XRD
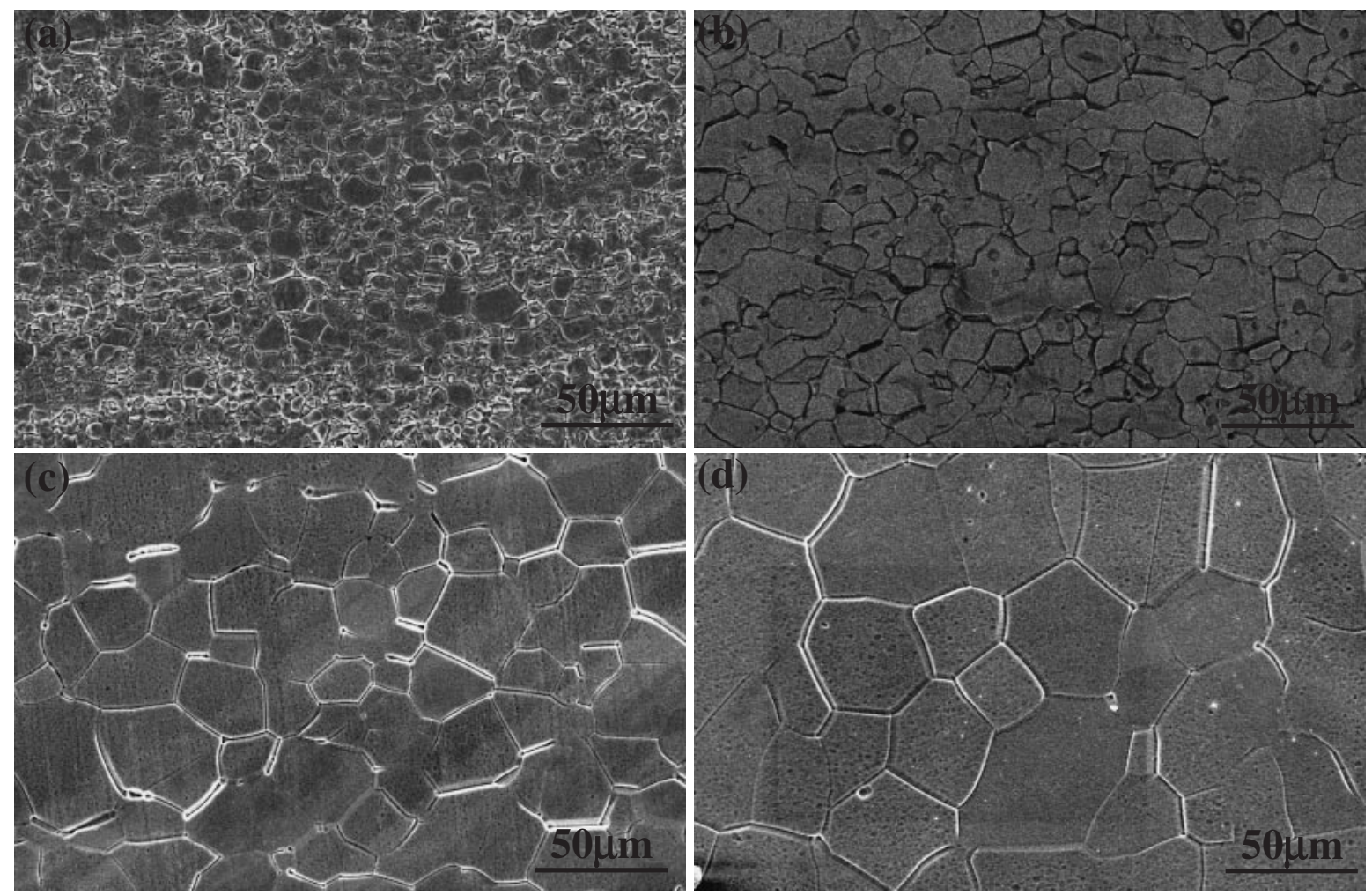

Fig. 2 SEM micrographs of the specimens annealed at (a) $873 \mathrm{~K}$, (b) $973 \mathrm{~K}$, (c) $1073 \mathrm{~K}$ and (d) $1173 \mathrm{~K}$. 

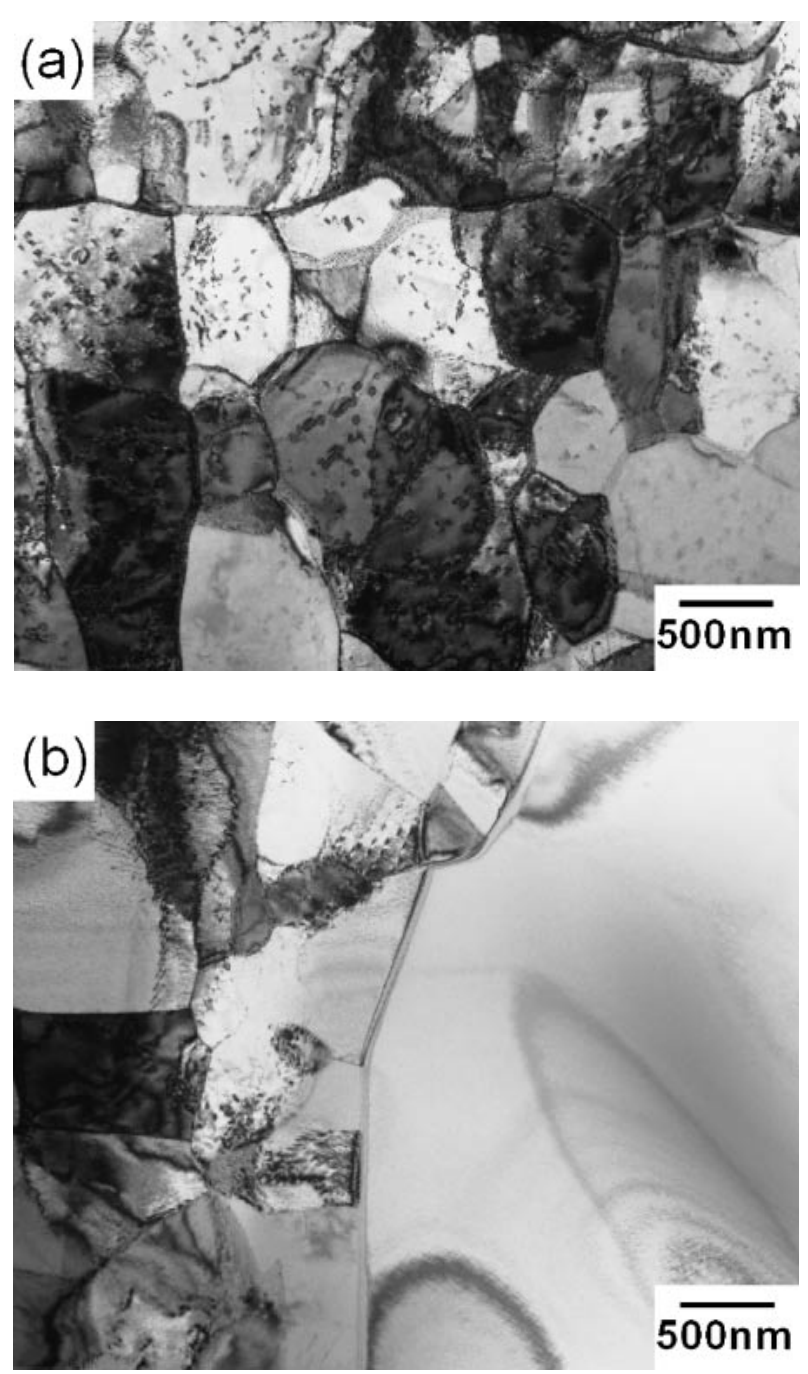

Fig. 3 TEM bright field micrographs of the specimens annealed at (a) $823 \mathrm{~K}$ and (b) $873 \mathrm{~K}$.

measurement. Figure 3 shows the bright field TEM micrographs of the specimens annealed at (a) $823 \mathrm{~K}$ and (b) $873 \mathrm{~K}$. In the specimen annealed at $823 \mathrm{~K}$, the subgrains with size of about $1.5 \mu \mathrm{m}$ are observed and the secondary phase is also observed. This secondary phase is identified to be $\alpha$ phase as shown in Fig. 4. On the other hand, a bimodal grain structure consisting of fine subgrains and large recrystallized grains is observed in the specimen annealed at $873 \mathrm{~K}$ as shown in Fig. 3(b). No secondary phase is observed in the specimen annealed at $873 \mathrm{~K}$.

Figure 4 shows bright field images and the corresponding selected area diffraction patterns (SADP) in the specimens annealed at (a) $823 \mathrm{~K}$, (b) $873 \mathrm{~K}$ and (c) $973 \mathrm{~K}$. Figure 4(d) shows the key diagram corresponding to Fig. 4(a). The beam directions are parallel to [100] of $\beta$ phase. As shown in Fig. 4(a), the secondary phase with size of $30 \mathrm{~nm}$ can be seen in the grains. In the SADP, diffuse spots at $1 / 2\{110\}_{\beta}$ and $1 / 2\{013\}_{\beta}$ can be seen in addition to primary reflections from $\beta$ phase. These spots can be identified to be $\alpha$ phase in Fig. 4(a). On the other hand, the $\alpha$ phase can not be detected in the specimens annealed at 873 and $973 \mathrm{~K}$ as shown in Figs. 4(b) and (c). These results of TEM observation are well consistent with the XRD measurement.
Figure 5 shows dark field TEM micrographs and the corresponding SADP of the specimens annealed at (a) $823 \mathrm{~K}$, (b) $873 \mathrm{~K}$ and (c) $973 \mathrm{~K}$. All SADPs were obtained from $[110]_{\beta}$ zone axis. In all SADPs, diffuse scattering at $1 / 3\{112\}_{\beta}$ positions corresponding to the $\omega$ phase can be seen in addition to the primary reflections from $\beta$ matrix. The spot indicated by a circle in each SADP was used to take the corresponding dark field micrograph. Dispersion of very fine $\omega$ particles with a dimension of $3 \mathrm{~nm}$ was observed in all dark field micrographs. It is clear that the density and size of the $\omega$ phase do not depend on annealing temperature. The $\omega$ phase is athermal one formed during quenching, since the thermal $\omega$ phase is formed by aging below $698 \mathrm{~K}$ in $\mathrm{Ti}-\mathrm{Nb}$ alloys. ${ }^{19)}$

The grain size was measured using SEM micrographs and it is plotted against the annealing temperature in Fig. 6. The grain size was measured by a linear intercept method. Based on the TEM observation, the subgrain size of the specimen annealed at $823 \mathrm{~K}$, about $1.5 \mu \mathrm{m}$, was also plotted. The grain size increases with increasing annealing temperature to $40 \mu \mathrm{m}$ at $1173 \mathrm{~K}$.

\subsection{Effect of annealing temperature on shape memory properties}

Figure 7 shows stress-strain curves of the specimens annealed at temperatures between 773 and $1173 \mathrm{~K}$. The tensile tests were carried out at room temperature. The specimens annealed at temperatures between 823 and $1173 \mathrm{~K}$ exhibit a two-stage yielding. The first stage yielding indicated by a black-headed arrow corresponds to the deformation of the stress-induced martensitic transformation because the $M_{\mathrm{S}}$ of these specimens is below room temperature as shown in the XRD measurement, SEM and TEM observation. The second stage yielding indicated by a whiteheaded arrow corresponds to the starting point of plastic deformation. The specimens annealed at $773 \mathrm{~K}$ exhibits a single-stage yield. Therefore, this specimen starts plastic deformation prior to the stress induced martensitic transformation. The fracture stresses and fracture strains were evaluated using the stress-strain curves of all the specimens, and they are plotted against annealing temperature in Fig. 8. The fracture stress decreases from 720 to $420 \mathrm{MPa}$ with increasing annealing temperature from 773 to $873 \mathrm{~K}$, and then exhibits similar values in the specimens annealed at temperatures between 873 and $1173 \mathrm{~K}$. On the other hand, the fracture strain increases with increasing annealing temperature from 7 to $29 \%$ due to the recovery and recrystallization.

In order to determine the martensitic transformation temperature, tensile tests were carried out at various temperatures. Figure 9 shows a series of stress-strain curves obtained at various temperatures for the specimens annealed at $873 \mathrm{~K}$. All the specimens were deformed to a strain of $2.5 \%$ followed by unloading. All the specimens were heated up to $500 \mathrm{~K}$ (above the reverse martensitic transformation finish temperature; $A_{\mathrm{f}}$ ) after unloading: lines with an arrow indicate the shape recovery by heating. The yield point, indicated by a larger arrow, is determined at the intersection of the stressstrain curve and a line parallel to the initial elastic portion of the stress-strain curve but offset by $0.2 \%$ from the origin as shown in Fig. 9. The shape memory effect was mainly observed for the specimens deformed at temperatures 

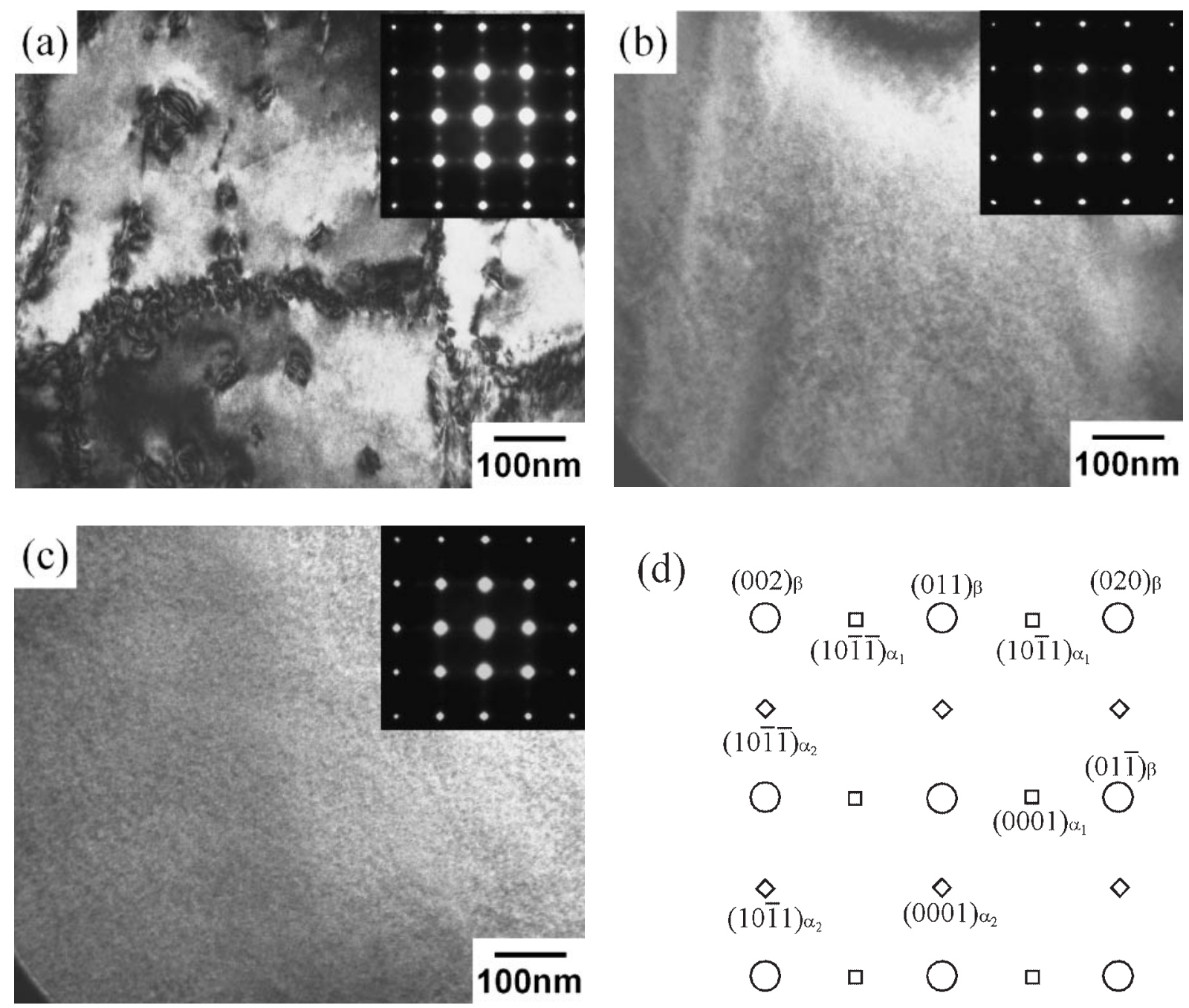

(d)

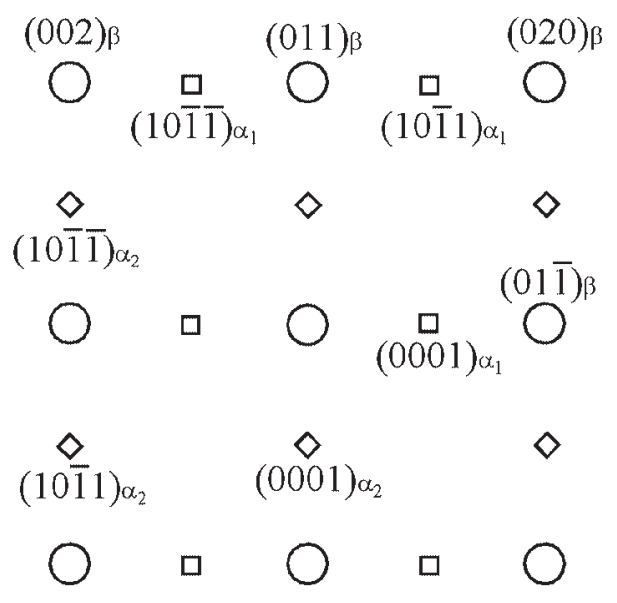

Fig. 4 TEM bright field micrographs and the corresponding diffraction patterns in the specimens annealed at (a) $823 \mathrm{~K}$, (b) $873 \mathrm{~K}$ and (c) $973 \mathrm{~K}$, (d) being a key diagram of the diffraction pattern.

between 173 and $233 \mathrm{~K}$. The residual strain after unloading was recovered by heating. The superelastic behavior was mainly observed for the specimens deformed at temperatures between 253 and $313 \mathrm{~K}$. However, the superelastic strain upon unloading decreases with increasing test temperature above $298 \mathrm{~K}$. The yield stress for each curve was plotted as a function of test temperature in Fig. 10. The results of other specimens annealed at various temperatures were also plotted in this figure. The yield stress in all specimens decreases with increasing test temperature to the minimum, and increases with further increasing test temperature. In general, the temperature exhibiting the minimum yield stress is taken as the martensitic transformation start temperature $\left(M_{\mathrm{s}}\right) ;$ e.g. $M_{\mathrm{S}}$ of the specimen annealed at $873 \mathrm{~K}$ is determined to be $233 \mathrm{~K}$. As shown in this figure, the $M_{\mathrm{s}}$ in all specimens were determined to be between 213 and $233 \mathrm{~K}$ irrespective of annealing temperature. According to these experimental results, it is confirmed that the $M_{\mathrm{S}}$ temperature is less affected by annealing temperature between 873 and $1173 \mathrm{~K}$.

Figure 11 shows stress-strain curves of a specimen annealed at $873 \mathrm{~K}$. Each stress-strain curve and recovery strain was obtained at room temperature by a loading and unloading cycle followed by heating: the strain recovery by heating being indicated by a broken arrow. The similar measurement was repeated by increasing the maximum strain by $0.5 \%$ upon loading in the same specimen. In order to characterize the shape memory behavior of the specimen, four types of strains are defined as follows; (1) the permanently remained strain $\varepsilon_{\mathrm{P}}$ after unloading followed by subsequent heating, (2) the elastic strain $\varepsilon_{\mathrm{E}}$ recovered elastically upon unloading, (3) the recovered strain $\varepsilon_{\operatorname{Tr}}$ due to the reverse transformation, i.e., the summation of the strain recovered superelastically upon unloading and strain recovered by heating and (4) the total recovered strain $\varepsilon_{\text {Tot }}$ consisting of $\varepsilon_{\operatorname{Tr}}$ and $\varepsilon_{\mathrm{E}}$. Almost complete superelastic behavior was observed in the first six curves, while the strain recovery by heating above $A_{\mathrm{f}}$ temperature in addition to the superelastic strain recovery was observed after the 7 th cycle. The plastic strain increases with increasing applied strain upon loading. Similar cyclic tensile tests were also carried out for other specimens.

The $\varepsilon_{\mathrm{E}}, \varepsilon_{\mathrm{Tr}}$ and $\varepsilon_{\mathrm{T} o t}$ estimated in Fig. 11 were plotted against the applied stress in Fig. 12. The $\varepsilon_{\mathrm{P}}$ starts to increase from $422 \mathrm{MPa}$. The $\varepsilon_{\mathrm{Tr}}$ and $\varepsilon_{\text {Tot }}$ increase to the maximum with increasing stress and saturate with further increasing stress. Generally speaking, the shape memory behavior can 

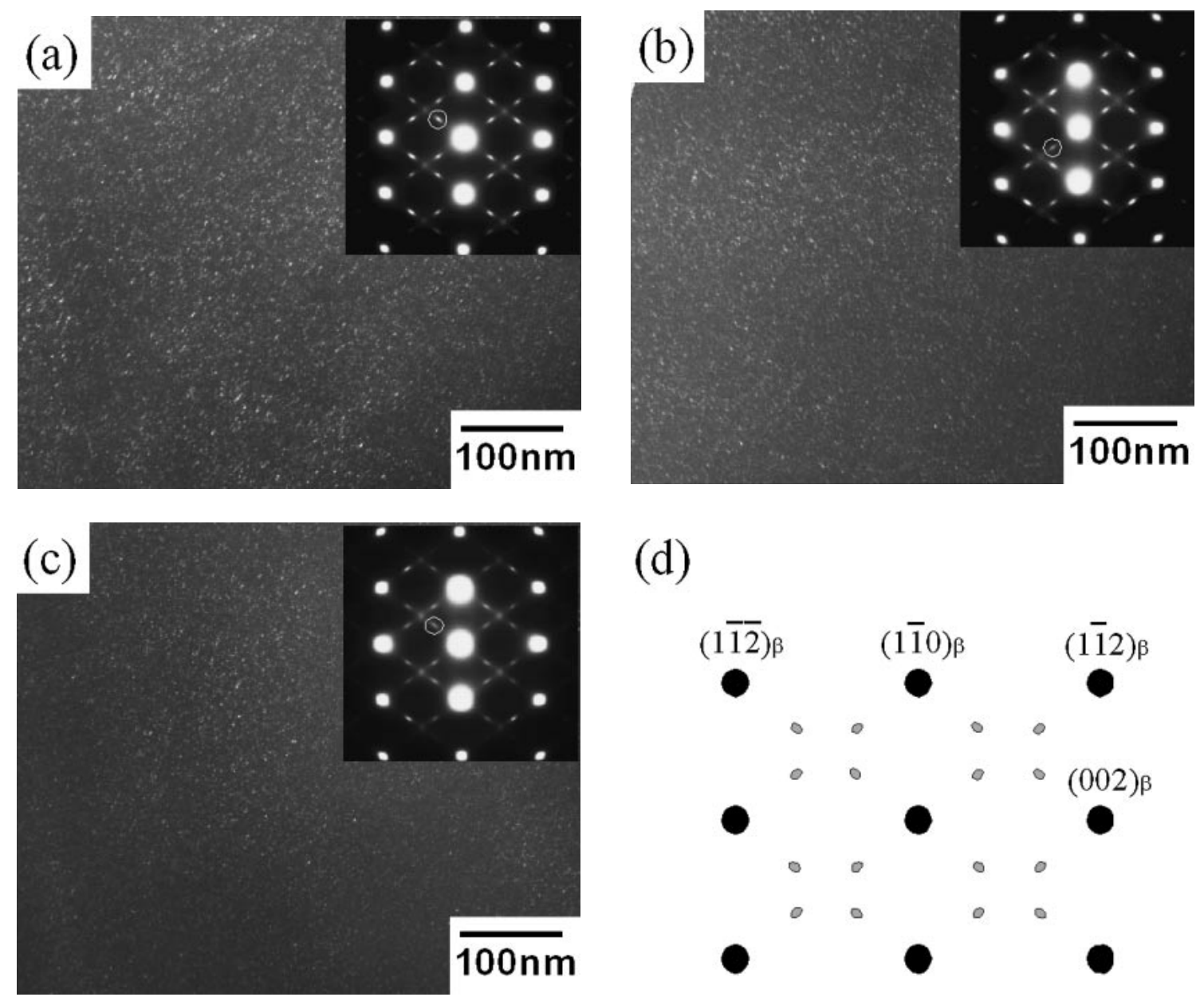

(d)

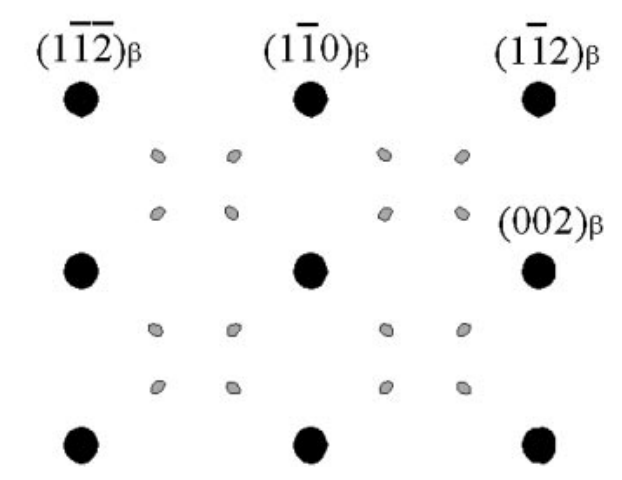

Fig. 5 TEM dark field images and the corresponding diffraction patterns in the specimens annealed at (a) $823 \mathrm{~K}$, (b) $873 \mathrm{~K}$ and (c) $973 \mathrm{~K}$, (d) being a key diagram of the diffraction pattern.

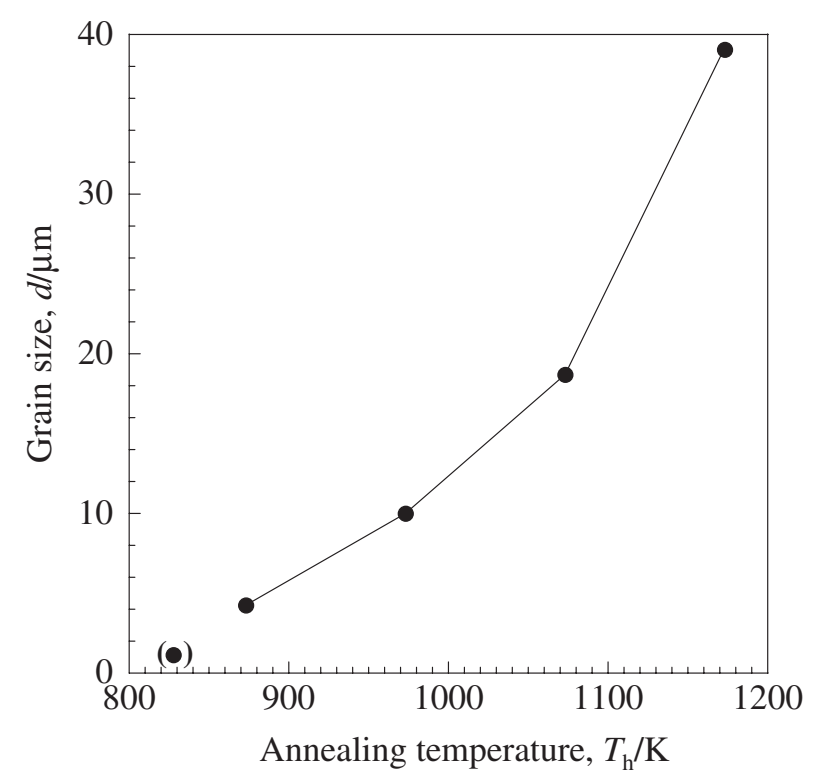

Fig. 6 Annealing temperature dependence of grain size in the specimens annealed at temperatures between 823 and $1173 \mathrm{~K}$.

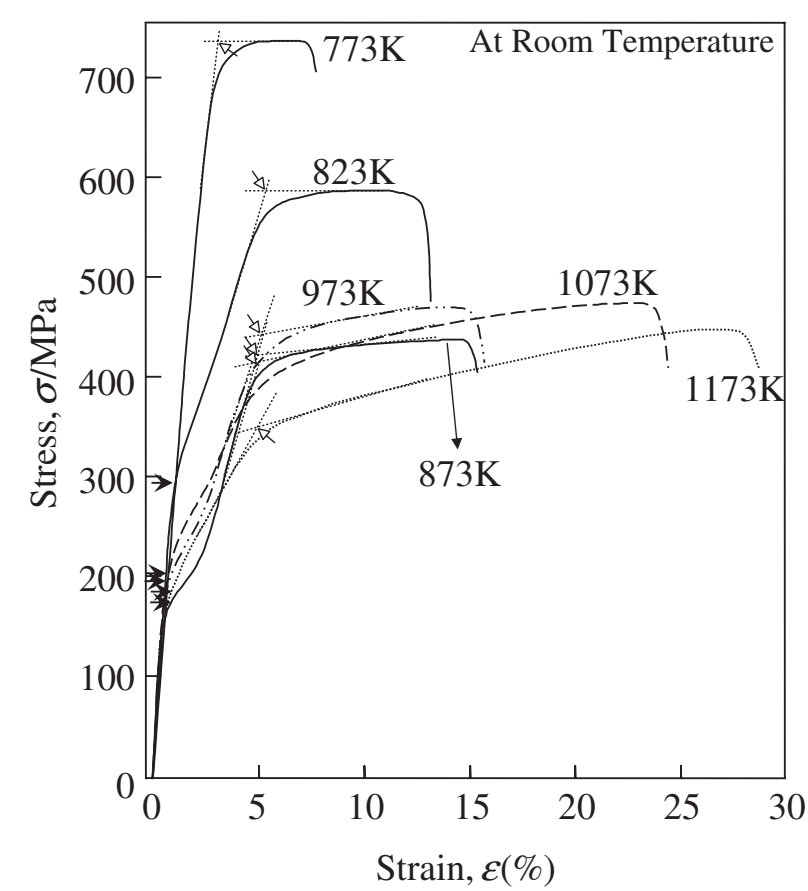

Fig. 7 Stress-strain curves obtained at room temperature in the specimens annealed at temperatures between 773 and $1173 \mathrm{~K}$. 


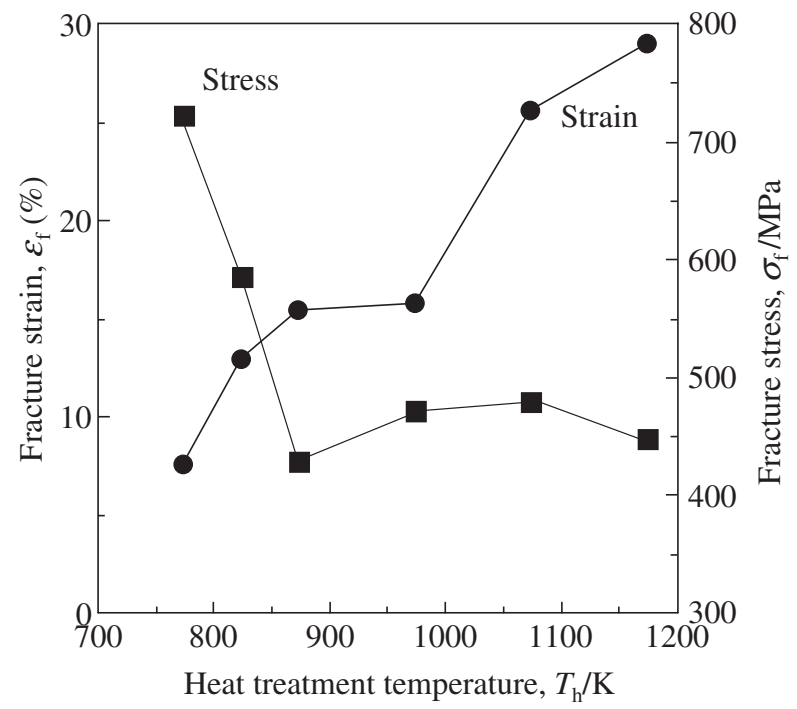

Fig. 8 Effect of annealing temperature on fracture stress and fracture strain in the specimens annealed at temperatures between 773 and $1173 \mathrm{~K}$.
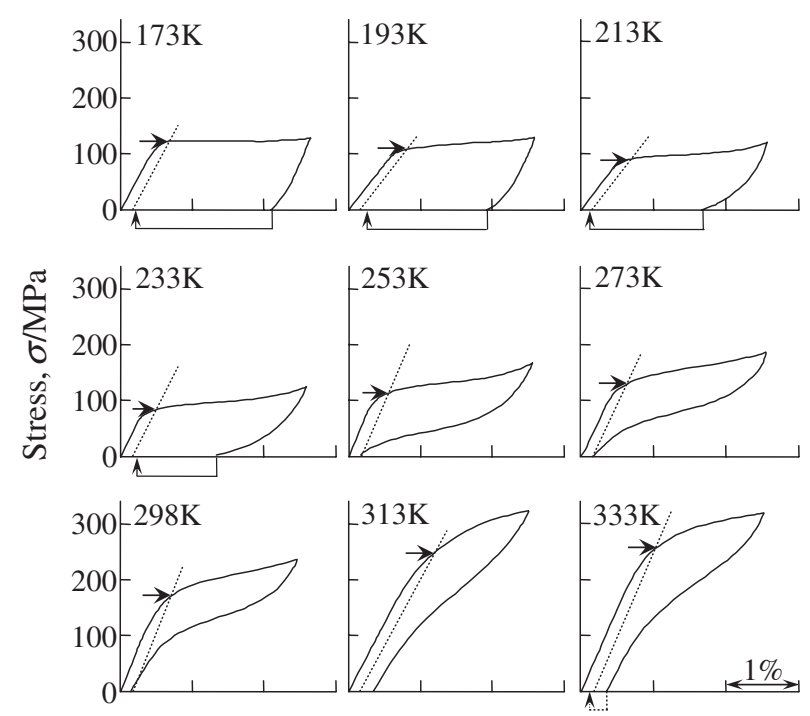

Strain, $\mathcal{\varepsilon}(\%)$

Fig. 9 Stress-strain curves obtained at various temperatures in the specimen annealed at $873 \mathrm{~K}$.

be characterized by the critical stress $\left(\sigma_{\mathrm{s}}\right)$ for slip, the maximum total recovery strain $\left(\varepsilon_{\mathrm{Tot}}^{\max }\right)$ and the maximum recovery transformation strain $\left(\varepsilon_{\operatorname{Tr}}^{\max }\right)$. The $\sigma_{\mathrm{s}}$ indicated by a white-headed arrow is defined in this study as the stress where $0.5 \%$ plastic strain is induced, while the $\varepsilon_{\text {Tot }}^{\max }$ indicated by a dashed arrow is the maximum total recovery strain and the $\varepsilon_{\operatorname{Tr}}^{\max }$ indicated by a black-headed arrow is the maximum recovery transformation strain as shown in Fig. 12. The $\sigma_{\mathrm{s}}$ is estimated to be about $460 \mathrm{MPa}$, while the $\varepsilon_{\mathrm{Tot}}^{\max }$ and $\varepsilon_{\mathrm{Tr}}^{\max }$ to be 4.9 and $2.8 \%$, respectively.

The $\sigma_{\mathrm{s}}, \varepsilon_{\mathrm{Tot}}^{\max }$ and $\varepsilon_{\mathrm{Tr}}^{\max }$ of the specimens are plotted against annealing temperature in Fig. 13. As shown in this figure, the $\varepsilon_{\mathrm{Tot}}^{\max }$ and $\varepsilon_{\mathrm{Tr}}^{\max }$ are almost constant irrespective of the annealing temperature. This indicates that the annealing temperature less affect the transformation strain. However,

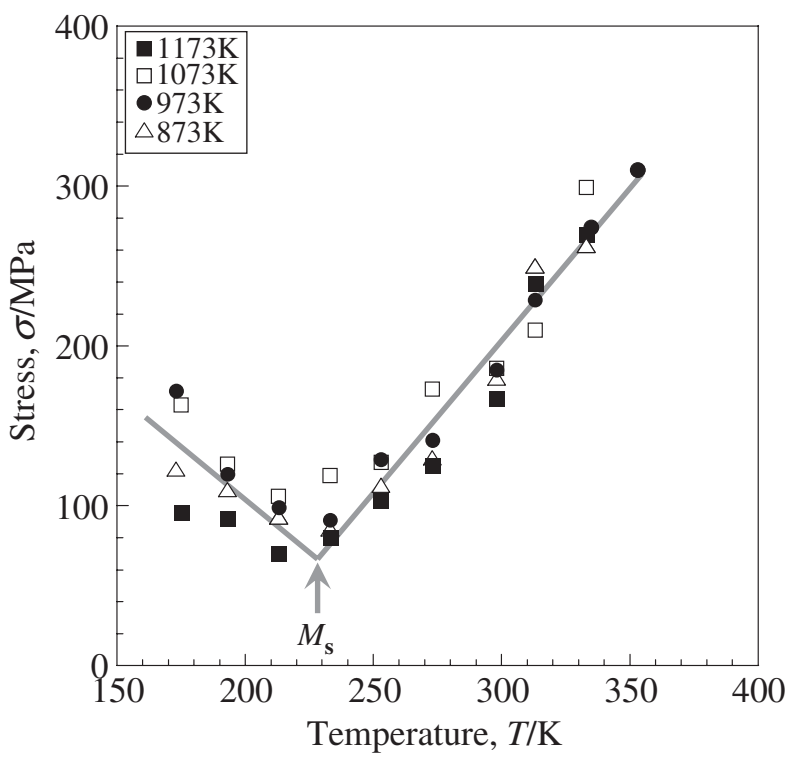

Fig. 10 Test temperature dependence of critical yield stress in the specimens annealed at temperatures between 773 and $1173 \mathrm{~K}$.

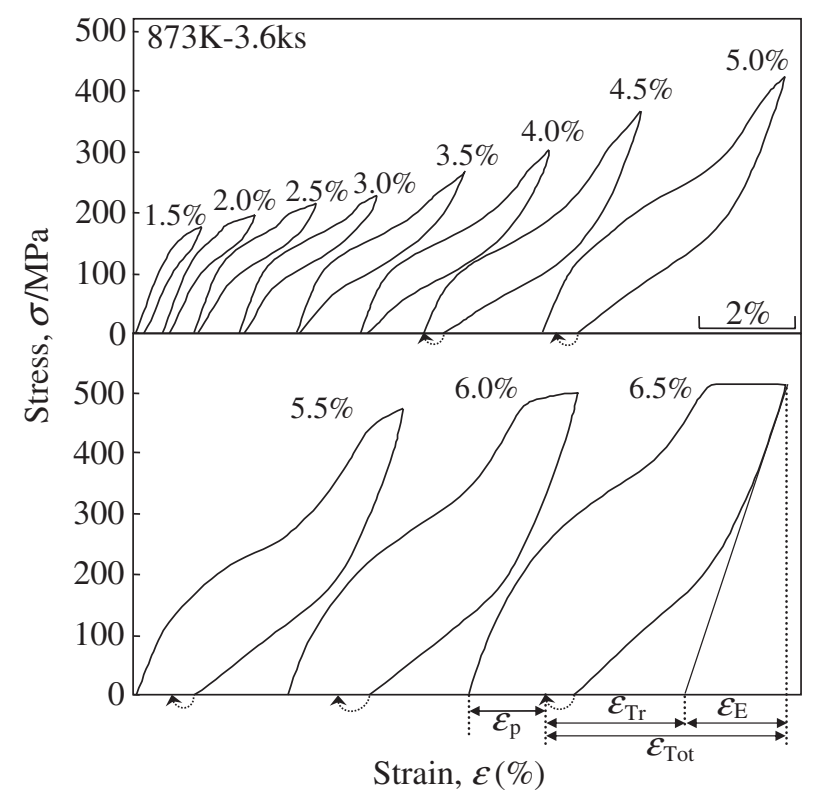

Fig. 11 Stress-strain curves obtained by cyclic loading-unloading tensile tests in the specimens annealed at $873 \mathrm{~K}$.

the $\sigma_{\mathrm{s}}$ decreases with increasing annealing temperature from $560 \mathrm{MPa}$ at $823 \mathrm{~K}$ to $315 \mathrm{MPa}$ at $1173 \mathrm{~K}$.

In order to apply Ti-based alloys to medical uses, the stability of superelasticity near body temperature is important. Cyclic tensile tests were carried out at room temperature. The specimens were elongated up to $2.5 \%$ strain followed by unloading at each cycle. The results for the specimens annealed at (a) $823 \mathrm{~K}$, (b) $873 \mathrm{~K}$ and (c) $973 \mathrm{~K}$ are shown in Fig. 14. All the specimens show an excellent superelasticity. In particular the specimen annealed at $823 \mathrm{~K}$ exhibits superior superelastic behavior with a narrow stress hysteresis as shown in Fig. 14(a). Although the first curve exhibits incomplete superelastic recovery with a plastic strain 


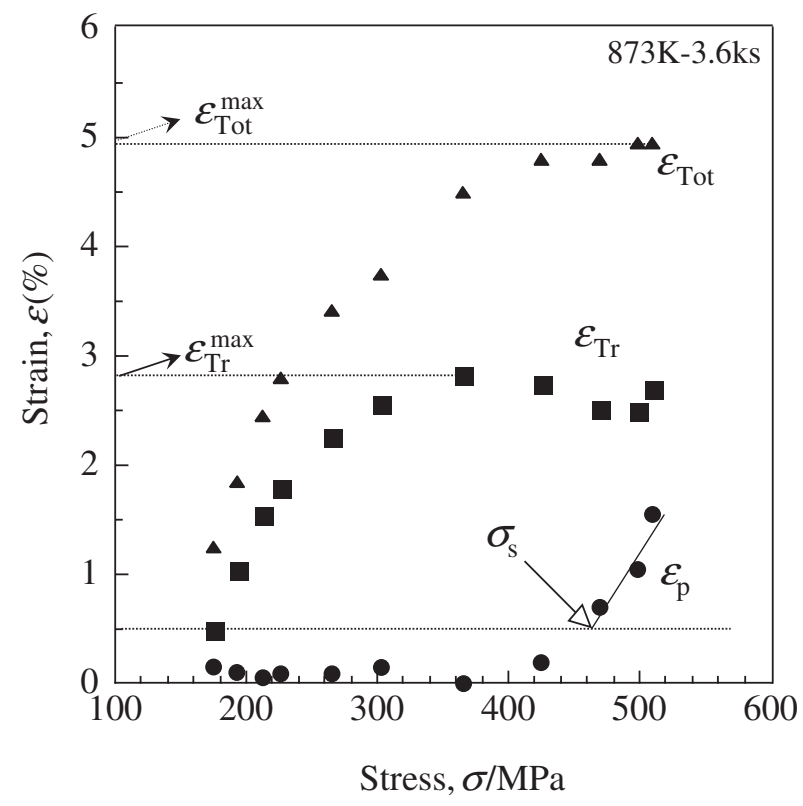

Fig. 12 Plastic strain $\left(\varepsilon_{\mathrm{P}}\right)$, total recovery strain $\left(\varepsilon_{\mathrm{Tot}}\right)$ and transformation recovery strain $\left(\varepsilon_{\mathrm{Tr}}\right)$ plotted against tensile stress in the specimen annealed at $873 \mathrm{~K}$.

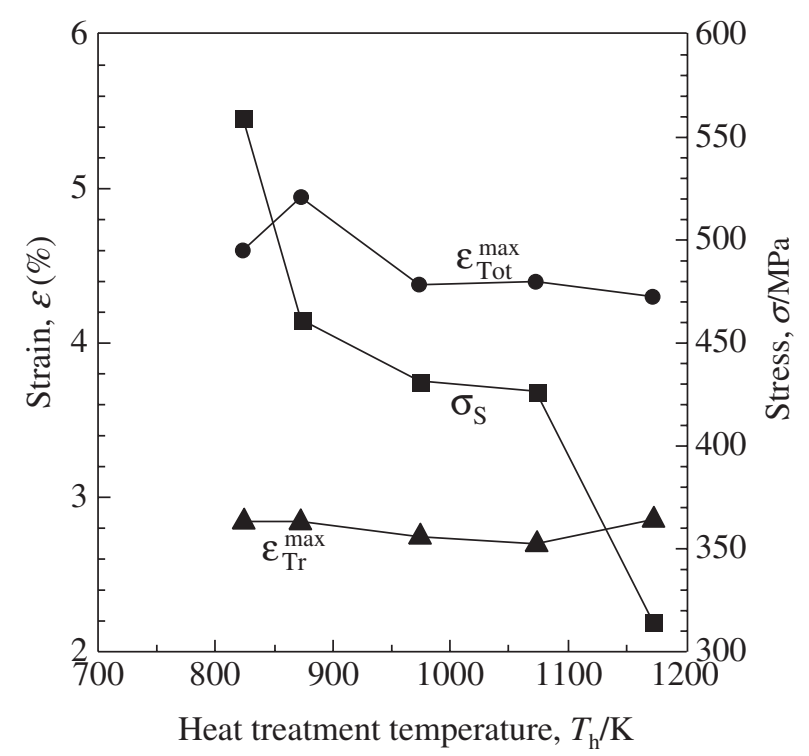

Fig. 13 Annealing temperature dependence of critical stress for slip $\left(\sigma_{\mathrm{S}}\right)$, maximum total recovery strain $\left(\varepsilon_{\mathrm{Tot}}^{\max }\right)$ and maximum recovery transformation strain $\left(\varepsilon_{\operatorname{Tr}}^{\max }\right)$ in the specimens annealed at temperatures between 823 and $1173 \mathrm{~K}$.

of $0.2 \%$, the curves after the 2nd cycle exhibit almost complete superelastic recovery. The yield stress indicated by an arrow decreases from $295 \mathrm{MPa}$ at the first cycle to $270 \mathrm{MPa}$ at the third cycle, then it becomes almost constant irrespective of increasing cyclic number. It is clear that this yield stress is higher than those of the specimens annealed at 873 and $973 \mathrm{~K}$. This is caused by the increase in the stress for inducing martensites due to the presence of $\alpha$ phase and fine subgrain structure for the specimen annealed at $823 \mathrm{~K}$ as shown in Figs. 3 and 4.

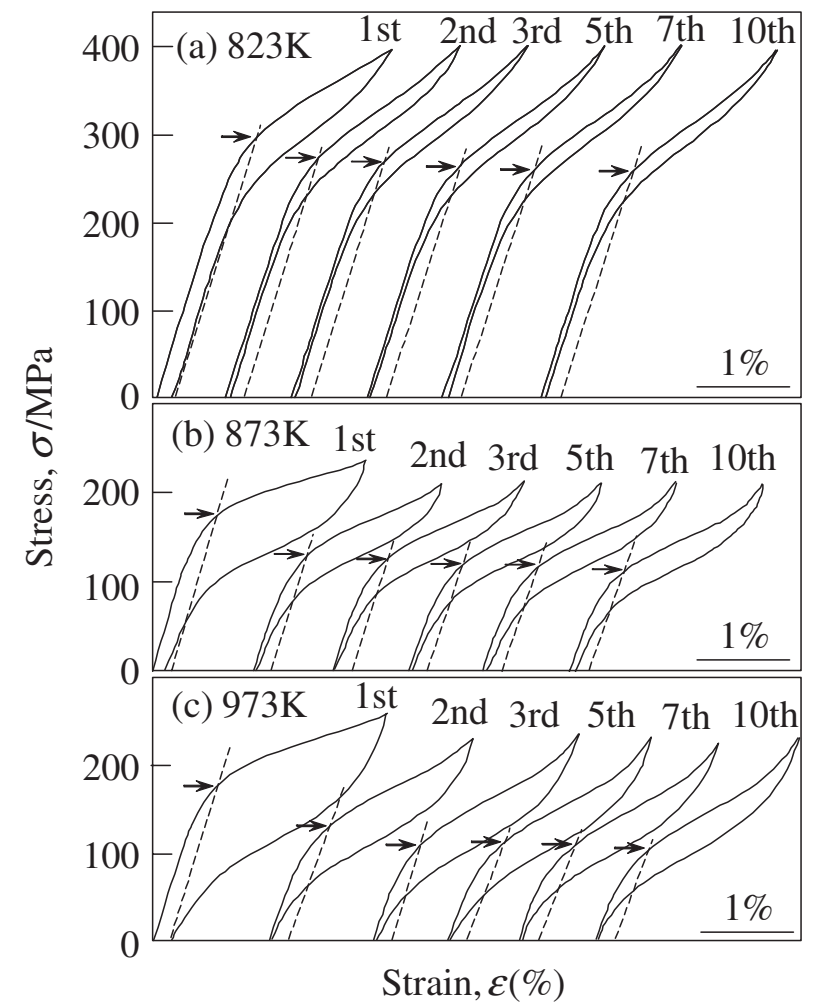

Fig. 14 Stress-strain curves obtained by repeated loading to the maximum strain of $2.5 \%$ followed by unloading at room temperature in the specimens annealed at (a) $823 \mathrm{~K}$, (b) $873 \mathrm{~K}$ and (c) $973 \mathrm{~K}$.

\subsection{Relation between microstructure and shape memo- ry properties}

The change of microstructure with increasing annealing temperature for the $\mathrm{Ti}-22 \mathrm{Nb}-6 \mathrm{Zr}$ alloy is summarized as follows. (1) The specimens annealed above $873 \mathrm{~K}$ exhibited the fully recrystallized structure while the specimen annealed at $823 \mathrm{~K}$ exhibited the fine subgrain structure. The grain size increased with increasing annealing temperature. (2) The texture changed from the $\{100\}\langle 110\rangle$ deformation texture to the $\{112\}\langle 110\rangle$ recrystallization texture with increasing annealing temperature. It is noted that the rolling direction is parallel to $\langle 110\rangle$ crystal directions in both textures. Thus, it is supposed that the effect of the texture change on mechanical properties is small in this study because the tensile direction is parallel to the rolling direction in all specimens. (3) The $\alpha$ precipitates were observed in the specimens annealed at 773 and $823 \mathrm{~K}$ while they were dissolved in the specimens annealed above $823 \mathrm{~K}$. As shown in Fig. 5, the fine athermal $\omega$ phase formed by quenching was observed in all specimens, indicating that the athermal $\omega$ phase is not related to the change of shape memory properties.

As mentioned above, the critical stress for $\operatorname{slip}\left(\sigma_{\mathrm{s}}\right)$ decreased with increasing annealing temperature. The specimen annealed at $823 \mathrm{~K}$ exhibited very high $\sigma_{\mathrm{s}}$ of $560 \mathrm{MPa}$, due to the $\alpha$ precipitates and fine subgrain structure. The drastic decrease in $\sigma_{\mathrm{s}}$ with increasing annealing temperature from 823 to $873 \mathrm{~K}$ is due to the recrystallization and dissolution of $\alpha$ precipitates. On the other hand, it is supposed that the decrease in $\sigma_{\mathrm{s}}$ between $873 \mathrm{~K}$ and 1173 is 


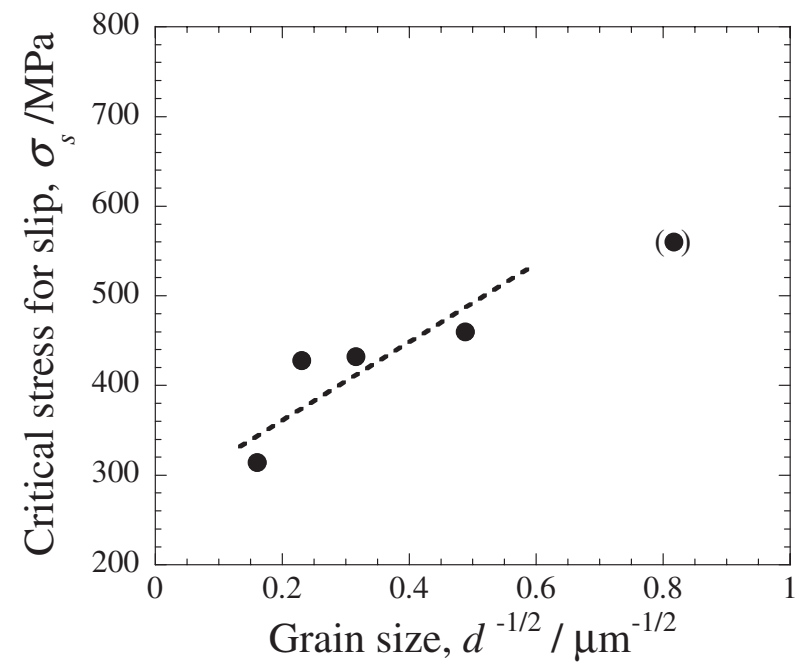

Fig. 15 Critical stress for slip $\left(\sigma_{\mathrm{S}}\right)$ as a function of grain size $\left(d^{-1 / 2}\right)$ in the $\mathrm{Ti}-22 \mathrm{Nb}-6 \mathrm{Zr}($ at $\%)$ alloy.

originated from the increase in grain size. Generally speaking, the Hall-Petch relationship, ${ }^{20,21)}$ has been applied to polycrystalline aggregates to explain the relationship between yield stress $\sigma_{y}$ and grain size $d$.

$$
\sigma_{y}=\sigma_{0}+k_{y} d^{-1 / 2}
$$

where $\sigma_{0}$ is a lattice friction stress and $k_{y}$ is the slope of the Hall-Petch relationship. The Hall-Petch slope $k_{y}$ depends on the resistance of grain boundaries to dislocation motion across the boundaries. It is expected that this relationship can be also applied to the relationship between the critical stress for slip and grain size in shape memory alloys. The critical stress for slip $\left(\sigma_{\mathrm{s}}\right)$ is plotted against grain size $\left(d^{-1 / 2}\right)$ in Fig. 15. The grain size of the closed circle in parentheses is an average diameter of subgrains estimated in TEM micrographs. It is seen that the Hall-Petch relationship qualitatively holds between the critical stress for slip and grain size. The Hall-Petch slop in this study is estimated at about $0.4 \mathrm{MN} / \mathrm{m}^{3 / 2}$. Further research is required to determine the $\sigma_{0}$ and $k_{y}$ precisely. It has been reported in literature that the value of $k_{y}$ is $0.25 \mathrm{MN} / \mathrm{m}^{3 / 2}$ in a $\alpha-\mathrm{Ti}^{22)}$ and $0.37 \mathrm{MN} / \mathrm{m}^{3 / 2}$ in a Ti-15.2 at\% Mo alloy, ${ }^{23)}$ respectively, suggesting that the value of $0.4 \mathrm{MN} / \mathrm{m}^{3 / 2}$ in the $\mathrm{Ti}-22 \mathrm{Nb}-\mathrm{Zr}$ alloy is considerably reasonable. Up to date, the quantitative researches on the effect of grain size on shape memory properties have hardly been reported. This present study revealed that grain refinement is a very effective method in order to improve the shape memory and mechanical properties in $\beta$-type Ti-based alloys.

\section{Summary}

The specimen annealed at $823 \mathrm{~K}$ for $3.6 \mathrm{ks}$ exhibited a fine subgrain structure. A bimodal grain structure with a fine subgrain and recrystallized grain was observed in the specimen annealed at $873 \mathrm{~K}$ for $3.6 \mathrm{ks}$, while a fully recrystallized structure was observed in the specimens annealed above $873 \mathrm{~K}$. The grain size increased with increasing annealing temperature. The annealing temperature slightly affected the transformation temperature and recovery strain. However, the critical stress for slip decreased considerably with increasing annealing temperature, because the grain size increased with increasing annealing temperature. The specimen annealed at $823 \mathrm{~K}$ exhibited excellent superelasticity due to fine subgrains and $\alpha$ precipitates. The HallPecth relationship holds between the critical stress for slip and grain size in the $\mathrm{Ti}-22 \mathrm{Nb}-6 \mathrm{Zr}(\mathrm{at} \%)$.

\section{Acknowledgments}

This work was partially supported by the ILC Project from University of Tsukuba the 21 Century Center of Excellence Program and the Grants-in-Aid for Fundamental Scientific Research Kiban A (1999-2001), Kiban A (2002-2004) from the Ministry of Education, Culture, Sports, Science and Technology, Japan.

\section{REFERENCES}

1) S. Shabalovskaya: Proc. First Inter. Conf. Shape Memory and Superelastic Technologies, 1994, 209.

2) T. W. Duerig, J. Albrecht, D. Richter and P. Fischer: Acta. Metall. 30 (1982) 2161-2172.

3) W. F. Ho, C. P. Ju and J. H. Chern Lin: Biomaterials 20 (1999) 21152122.

4) T. Grosdidier and M. J. Philippe: Mater. Sci. Eng. A 291 (2000) 218223.

5) H. Hosoda, N. Hosoda and S. Miyazaki: Trans. MRS-J 26 (2001) 243246.

6) H. Y. Kim, Y. Ohmatsu, J. I. Kim, H. Hosoda and S. Miyazaki: Mater. Trans. 45 (2004) 1090-1095.

7) T. Maeshima and M. Nishida: Mater. Trans. 45 (2004) 1096-1100.

8) T. Maeshima and M. Nishida: Mater. Trans. 45 (2004) 1101-1105.

9) C. Baker: Mater Sci. J. 5 (1971) 92-100.

10) H. Y. Kim, S. Hashimoto, J. I. Kim, H. Hosoda and S. Miyazaki: Mater. Trans. 45 (2004) 2443-2448.

11) K. Nitta, S. Watanabe, N. Masahashi, H. Hosoda and S. Hanada: Structural Biomaterials for the 21st Century, (TMS, 2001) 25-34.

12) H. Hosoda, Y. Fukui, T. Inamura, K. Wakashima, S. Miyazaki and K. Inoue: Mater. Sci. Furum 425-432 (2003) 3121-3124.

13) T. Inamura, Y. Fukui, H. Hosoda, K. Wakashima and S. Miyazaki: Mater. Sci. Eng. C 25 (2005) 426-432.

14) J. I. Kim, H. Y. Kim, H. Hosoda and S. Miyazaki: Mater. Trans. 46 (2005) 852-857.

15) J. I. Kim, H. Y. Kim, T. Inamura, H. Hosoda and S. Miyazaki: Mater. Sci. Eng. A. 403 (2005) 334-339.

16) S. G. Steinemann: Evalution of Biomaterials, Ed. By G. D. Winter, J. L. Leray and K. de Goot, (John Wiley \& Sons, Ltd., 1980) 1-34.

17) H. Y. Kim, T. Sasaki, K. Okutsu, J. I. Kim, T. Inamura, H. Hosoda and S. Miyazaki: Acta Mater. 54 (2006) 423-433.

18) T. Inamura, Y. Fukui, H. Hosoda, K. Wakashima and S. Miyazaki: Mater. Trans. 45 (2004) 1083-1089.

19) D. L. Moffat and D. C. Larbalestier: Metall. Trans. A 19A (1988) 1687-1694.

20) E. O. Hall: Pro. Phys. Soc. Lond. B64 (1951) 747-753.

21) N. J. Petch: J. Iron Steel Inst. 174 (1953) 25.

22) H. Conrad: Prog. Mater. Sci. 26 (1981) 123-403.

23) K. H. Chia, K. Jung and H. Conrad: Mater. Sci. Eng. 409 (2005) 32-38. 